\title{
Beyond classroom walls: The role of a co-curricular English club in supporting second language learning
}

\section{Jennifer Sheokarah}

School of Education, University of KwaZulu-Natal, Durban, South Africa

jennifer_sheokarah@yahoo.com

https://orcid.org/0000-0003-4233-6752

\section{Ansurie Pillay}

School of Education, University of KwaZulu-Natal, Durban, South Africa

Pillaya3@ukzn.ac.za

https://orcid.org/0000-0002-9174-0543

(Received: 7 January 2020; accepted: 1 November 2020)

\section{Abstract}

Second language learners of English in South Africa and beyond face challenges in acquiring the target language. In this paper, we report on a study during which we worked with an English Language Club set up as a co-curricular activity at a South African high school. We focus on one activity of the club that took place beyond the classroom walls to help learners improve their spelling. While the activities of the club were underpinned by critical pedagogy, we interpreted the findings of the study using Krashen's Affective Filter hypothesis. Using a critical paradigm, a qualitative approach, and an action research design, in this aspect of the study, as foregrounded in this paper, we aimed to answer the question of how learners' attitudes towards spelling may be changed by an activity outside the classroom. Our observations, fieldnotes, and reflections revealed that learners are able to transcend their fear of the language and increase their participation levels when they are in a relaxed learning environment that values their interests; this increased, in turn, their selfconfidence. We argue for the use of alternative teaching methods to complement conventional teaching and learning.

Keywords: second language learners, co-curricular, English Language Club, spelling, relaxed environment

\section{Introduction}

In South Africa, most schools use an African language as the medium of instruction in the first three years of school and then switch to either English (mostly) or Afrikaans in the learner's fourth year of school as Pretorius and Stoffelsma (2017) have reminded us. The language profile of 51.7 million South Africans indicates, as Howie et al. (2017) have noted, 
that $24 \%$ speak isiZulu, $16 \%$ speak isiXhosa, and $14 \%$ speak Afrikaans, while only $10 \%$ speak English. In other words, most learners are English second language speakers but are taught their subjects in English as noted by Schaefer and Kotzé (2019). Literacy studies conducted with South African English Second Language learners reveal poor literacy scores. Pretorius and Spaull (2016) have recommended that interventions are needed to enhance English Second Language learners' literacy skills, in light of the various contextual challenges they face, especially in schools with poor or no resources and with large numbers in classes, and the fact that many of these learners have no access to English resources at home. In addition, learners in South African rural areas are not usually exposed to English in their communities where they speak their home language as Schaefer and Kotzé (2019) have pointed out. This is the context of the school cited in this study. Learners speak isiZulu at home but learn English as the home language at school and are taught through the medium of English.

In this paper, we reflect on one activity in an action research study that involved working with an English Language Club to support the learning of English. The four cycles of the study focused on listening and speaking in cycle one, spelling and vocabulary in cycle two, reading in cycle three, and writing in cycle four. We focus here on a spelling activity in cycle two; our research question was: How may English second language learners' attitudes towards spelling be improved by activities in a co-curricular English club beyond the classroom walls?

Spelling in any language, including English, is an important foundation for effective reading and writing (Fleisch et al., 2017; Hashemi \& Ghalkani, 2016). However, findings by the latter, in their study of spelling errors of a random sample of learners in 100 schools in KwaZulu-Natal, revealed that most learners could not spell the words they needed to read and write effectively. They recommended interventions to enhance second language learners' ability to spell.

While effective interventions could go a long way towards addressing the challenges of learning a second language, studies reveal that interventions may be hampered by learners' anxiety when they are learning a language such as English (Madonsela, 2015). To overcome anxiety among such learners, a creative, experimental, enjoyable atmosphere needs to underpin the interventional strategies to help eliminate the stress of learning the language and to encourage participation (Dewi et al., 2017). With this idea in mind, an English Language Club (ELC) was formed in the school in which this study was located.

\section{The English Language Club (ELC)}

At the school, English, taught as a home language and as the medium of teaching and learning, excludes learners' home languages and it is presented as the language of power. Learners have difficulty using English and seem to lack motivation to learn how to speak it. In many classes, participation in English is minimal. In response to the situation, the ELC, which is a co-curricular club open to learners in grades 8 and 9, was created by the primary 
researcher and first author (an English teacher at the school) to offer learners creative opportunities to engage with English in an environment away from the formal classroom. The ELC is comprised of 30 members but the numbers attending each week vary. Members meet for an hour once a week and attendance is voluntary, in line with the understanding of Alexander et al. (2011) that ELCs are usually free, informal, and involve individuals meeting voluntarily to practise English. As co-curricular activities, these ELCs include group experiences and differ from the conventional academic curriculum that has "well defined monitoring mechanisms" (Pereira et al., 2013, p. 49). The purpose of such clubs includes allowing opportunities for learning in ways that school classrooms do not offer; they foster motivation in a supportive space that empowers learners to read and write and they encourage an experimental and explorative mindset in a warm and welcoming atmosphere so as to stimulate interest in learning and improving knowledge and usage of the language (Alexander et al., 2011; Pereira et al., 2013). Given their ethos, the purpose and composition of such clubs are comparable with the maths clubs set up in primary schools in the Eastern Cape, South Africa, by Graven (2011) and the economics clubs set up by Acquah and Partey (2014) in Ghana. Like the maths club, the ELC in this study aimed at enjoyment even as it shifted responsibility to learners to identify their areas of weakness in the subject. Like both the maths and economics clubs, the ELC worked as a co-curricular activity that aimed to improve learner competence in the subject.

Following Alexander et al. (2011) and Pereira et al. (2013), such clubs foster a safe, stressfree, relaxed, nurturing, non-threatening, and respectful environment in which the aim is not to demand answers or correct errors but, rather, to guide those who join, and to facilitate and encourage the exchange of ideas. Simple encouragement and praise, or rewards, prove to be effective as Goss et al. (2017) have noted elsewhere.

Similarly, the ELC under consideration in this study used innovative fun activities, sometimes with an element of competition with symbolic rewards suggested by the learners. The club motivated the members to succeed at learning English through its use of competitions and rewards that were linked to the skills the learners needed to develop.

Dialogue was encouraged during the activities and learners made their voices heard as they took control of their learning. In terms of the spelling activity specifically, on which we focus in this paper, we worked together to find activities that would improve their attitudes towards spelling. Learners voiced the need to get out of the classroom and this resulted in a beach spelling activity.

\section{Theoretical framework}

\section{Critical pedagogy}

Critical pedagogy cultivates democracy, encourages critical thinking, and encourages learning in creative ways rather than through the memorisation of material (Halabsaz \& Hedayati, 2016). For Camangian (2015), a principle of critical pedagogy is that of humanisation. Humanising pedagogies draw on learners' experiences and empower them 
socially, emotionally, intellectually, and politically by using cultural references and lived experiences to convey knowledge and skills and to change attitudes. The ELC employed a humanising pedagogy by fostering a safe, comfortable, fun, and nurturing environment that encouraged learner participation and improved their self-esteem when they were learning English. In the baseline study with 27 learners prior to setting up the ELC, mind-maps reflected the challenges they faced in learning English. These included feeling shy or scared when using the language, the fear of being mocked for errors made, and anxiety when speaking to persons of race groups other than their own.

The baseline study reflected that of Norton and Toohey (2004) who argued that language is not only viewed as a method of communication, but it influences and is influenced by learners' understanding of their social contexts. The baseline data made clear the need for a humanising pedagogy if learners were to improve their English. Other baseline data of interest to this paper is the finding that 21 (of 27) learners who identified spelling as a major challenge, cited a fear of spelling in English along with the poor marks received for spelling tasks in class. The baseline data revealed the need to introduce strategies to encourage their agency so that they could confront their feelings of marginalisation in the English classroom.

To foster human agency so as to challenge exclusion, learners were encouraged to question and reflect on activities and experiences. They were asked to decide if and how any of these helped them learn better and how and what they would like to change to increase their motivation to learn English and to improve this learning. We aimed for critical consciousness and learners, in their roles as planners and implementers of activities to improve their English competence, became empowered as they assumed responsibility for their own learning. They did so by thinking critically about their strengths and weaknesses and questioning what worked and did not work for them. In line with the ideas of Aliakbari and Faraji (2011) and Camangian (2015), learning critical thinking skills and developing their critical consciousness allowed them to become aware of what might be done to change their situation as they learned the language. We saw critical consciousness being used to enable a transformative teaching and learning process as learners became active learners, and, by extension, active citizens.

Dialogue was essential in the ELC to engage and actively involve learners in their learning and in their construction of meanings as advocated by Freire (1970). A dialogic approach (see Camangian (2015) and Mazdaee and Maftoon (2012)) enabled questions, contributions, and led to a change in their understanding of learning a language. In line with the principles of critical pedagogy (Aliakbari \& Faraji, 2011; Batker et al., 2017), learners' views were heard and respected. They were encouraged to engage actively through dialogue in their construction of knowledge instead of being merely passive recipients.

\section{Krashen's Affective Filter hypothesis}

While critical pedagogy underpinned the formation of the club, we used Krashen's Affective Filter hypothesis to analyse the findings of the study. This hypothesis is based on the notion that input is filtered according to learners' moods. Affective variables such as motivation, 
self-confidence, and anxiety play a role in second language acquisition (Kakule, 2016; Krashen, 1982; Nath et al., 2017). These variables shape the success of second language acquisition as Du (2009) and Krashen (1982) have pointed out. Put briefly, the higher the learner's motivation, the lower her/his affective filter is, so the more successful she/he becomes. If the learner's self-esteem is low, the higher her/his fear of making mistakes becomes and this results in the loss of opportunities to practise the language ( $\mathrm{Du}, 2009)$. The lower the learner's anxiety, the more effective the language acquisition is (Krashen, 1982). If learners are afraid of being with others, communicating with others, and taking tests, their anxiety may inhibit language acquisition (Du, 2009).

With an understanding of the Affective Filter hypothesis, teachers are encouraged to create classroom environments that are designed to motivate learners to participate in learning English (Kakule, 2016). The idea is to eliminate a stressful atmosphere by using relaxed and fun activities to motivate learners and lower the affective filter (Abukhattala, 2013; Kakule, 2016). Nath et al. (2017) have argued that outdoor activities are most effective for doing so. Groupwork and social activities are also important since they lower anxiety and boost confidence (Du, 2009).

Both theories worked seamlessly to underpin the ELC and to help us understand the findings since the concepts complement each other. The humanising ethos of critical pedagogy empowers learners within a safe relaxed environment, which plays a positive role in language acquisition. Enabling critical consciousness creates active learners working in dialogic spaces of respect which allow for an increase in their self-confidence, which further increases their motivation to learn English.

\section{Literature review}

Becoming proficient in a language requires mastering the skills of listening, speaking, reading, and writing which may be challenging for second language learners (Al-Bereiki \& Al-Mekhlafi, 2016). As a result, learners who lack proficiency in English may be afraid to speak because they fear making mistakes or being laughed at by their peers in the classroom. Their lack of confidence and their fear of expressing ideas may result from a lack of necessary vocabulary and the related spelling of these words, as has been revealed in the action research study of Dewi et al. (2017). Similarly, in South Africa, Madonsela's (2015) study found that African second language learners who lack proficiency in English suffer similar affective issues.

When English becomes the medium of instruction in grade four in most South African schools, teachers assume that learners arrive from grade three with a good foundation in the necessary vocabulary and spelling skills, but, given the ripple effect, there is a significant gap between the words learners know by the end of grade four and the words they need to know in grade five (Pretorius \& Stoffelsma, 2017), and this continues from year to year. There is a strong relationship between attaining a vocabulary and reading. If learners know fewer words, they will not be able to comprehend as much as they need to in order to follow a text 
(Pretorius \& Stoffelsma, 2017). There is also a strong relationship between spelling and being able to read and write (Fleisch et al., 2017; Sibanda \& Baxen, 2018). The studies by Fleisch et al. and Pretorius and Stoffelsma both concluded that spelling errors were common among second language learners and pointed to the effect of this on reading and writing. Learners, too, understand the importance of spelling. In a study with 75 English second language high school learners in Nigeria, Aliyu and Danladi (2018) found that learners understood the importance of spelling if they were to improve their writing in English. A similar finding emerged from a study in Malaysia by Al-Sobhi et al. (2018) on the attitudes towards spelling of English second language high school learners.

If teachers understand the importance of spelling, and second language learners recognise its importance while dealing with the affective factors related to learning a second language, it becomes necessary to consider how spelling is taught. Hashemi and Ghalkani (2016) found that the strategy of teaching spelling traditionally included teachers providing learners with lists of words, the spelling of which learners needed to memorise. Learners were also asked to correct spelling errors in their and their peers' written tasks. Findings indicated that memorisation was short lived, and learners later spelled the words on the list incorrectly. Additionally, it was noted that teachers expected learners to memorise how to spell words, in rote-learning fashion, without teaching them the techniques of spelling (Hashemi \& Ghalkani, 2016).

In response to such ways of teaching, Sibanda and Baxen $(2018$, p. 8) argued for a variety of strategies that move beyond repeating words in "a mechanical rather than a cognitive process" and Denkci-Akkas and Coker (2016) suggested an approach to spelling that is relaxed, that encourages learners to participate, that motivates learners, and helps them learn from each other. As Pereira et al. (2013) pointed out, the more conducive and supportive the environment is, the more successful the learning outcomes are because there is a positive relationship between the learning environment and learner motivation.

To create a positive language learning environment, the choice of teaching strategies is vital since they boost the learners' performance of the language (Chamorro \& Paz, 2017). In designing activities, it is important to encourage communication, eliminate constraints, and choose activities that will interest learners (Pereira et al., 2013). Dewi et al. (2017) suggested the use of non-formal education such as song, dance, tales, theatre, technology, games, and recreational activities that extend outside the classroom so as to provide conditions in which learners learn more effectively. Hashemi and Ghalkani (2016, p. 736) suggested that teachers offer learners opportunities "with modern and scientific methods and techniques for learning" and provided an example of a personalized instructional technique that had learners making connections between words and their favourite things (like television programmes or cartoon characters). This resulted in the learners making associations between the letters of the word and the things that allowed for better mental storage of the letters that helped their spelling. 


\section{Methodology}

\section{Ethics}

Ethical procedures were followed by our gaining consent from parents and learners. We assured the learners of all their ethical rights including voluntary participation, their right to anonymity and confidentiality and the right to withdraw from the study at any point without penalty. Learners were also made aware that they could participate in the ELC but choose not to give consent to be a part of the study. All learners and their parents gave consent to participate. While the ELC worked with 30 regular members at the time of the beach spelling activity, because of learners' religious obligations, only 10 learners from grade 9 (average age 14 years) participated in the beach spelling track activity, held on a Saturday morning.

\section{Critical paradigm}

A critical paradigm emphasises the need for developing social transformation and moving towards emancipation. It provides opportunities which help emancipate those who are subordinated and who lack voice and agency because of feeling excluded by providing more liberating environments and fewer challenging circumstances that serve to restrict people (Harney, 2014). This paradigm was suitable for our study since learners in the school come from language backgrounds that are not prioritised in the school, and we aimed to give them voice and enable transformation.

\section{Qualitative approach}

A qualitative approach was appropriate since, following Cohen et al. (2011) we wanted to work closely with learners to understand their challenges, strengths, and weaknesses and empower them by facilitating their ability to speak and write English. Furthermore, a qualitative approach allowed for descriptions and interpretations of the experiences of learners throughout the study. It enabled us to focus on the process of how the study was unfolding in its natural context.

\section{Action research design}

This research used a participatory action research design which is useful for understanding and improving practices as Cohen et al. (2011) have observed. Since the growth of all participants is key to participatory action research, this involved our noticing a challenge, identifying who was affected by it and working together to plan and implement effective strategies to deal with it and then analyse the results of the study.

Participatory action research was also appropriate in this setting since the process allowed for both the teacher and the learners to attempt to change the teaching and learning environment through active participation and critical reflection, and to do so through the activities of the English club. As part of this process, the teacher attempts to change the way learners learn by better understanding the effects of his/her teaching methods and modifying them accordingly. 
Action research involves many cycles, each of which includes the stages of planning, acting, observing, and reflecting. Each cycle serves to revise the research process and inform the next cycle (Cohen et al., 2011). It was within one of these cycles that learners in the ELC articulated their fear of spelling. The learners had completed a spelling activity that involved unscrambling words and had just completed a spelling relay activity done in the classroom. The spelling relay activity, involving sixteen learners who were randomly divided into two groups, worked with a list of words that learners had spelled incorrectly in their English classrooms. Learners stood in separate lines in front of a table that had a sheet of paper on it for each line. The teacher called out the first word in the list and the first learner from each group had to move quickly to the table and write out the word on the piece of paper, go back to the line and pass the pen to the next learner. Once one of the two learners started moving back to the line, the second word was called out. The group to spell the most words correctly was announced the winner of the spelling relay. While the competitive activity was accompanied by much noise and laughter, the reflection activity thereafter revealed learners' fear of spelling. The learners suggested an outdoor activity that would enable them to practise their spelling in a relaxed environment. A decision, taken collaboratively, resulted in a beach spelling activity on a section of the beach that included a jungle gym, which served as a spelling track. Learners had to complete a flashcard activity in preparation for the beach spelling activity.

For this activity, learners had to start at one point and take turns to spell a word that was called out. A ball was thrown to them to indicate when they needed to spell the word out loud. Spelling the word correctly meant that the learner would move to the next point of the spelling track. If the spelling was incorrect, he/she had to move to the end of the line until his/her next turn. The winner of the spelling track - the learner who spelled the most words correctly and crossed the finish line first-received a box of chocolates and a medal.

\section{Data generation methods}

\section{Observations}

This study used observations to generate data from "naturally occurring situations" (Cohen et al., 2011, p. 456) by closely noting events and learners' behaviours. This allowed for documentation of what was taking place as it happened. The observation of the beach spelling track activity focused not only on the correctness of spelling out loud, but also on how the learners responded to their spelling and to one another in terms of their facial and verbal expressions during the activity, and how they responded to the outside environment of the beach.

\section{Fieldnotes}

Writing our fieldnotes involved objectively recording observations that we made in the setting or immediately afterwards as advised by Newbury (2001). Our fieldnotes recorded what happened during spelling activities in the ELC, what activities were done and how they were done, and how many learners were present at the sessions. We recorded the proceedings 
of the specific spelling activity conducted at the beach as well as keeping account of related events outside the club that we considered influential to both the club and the research process in terms of how the learners responded to the beach activity.

\section{Reflections}

Reflection is integral to action research since it is used to inform the research process as we know from Cohen et al. (2011). Reflections on the challenges or concerns are then used to design the subsequent interventions to address these and other issues. In this study, the instruction sheet advised learners to write a paragraph reflecting on their journey through the spelling activities. They were asked to write about what they had experienced and whether the activities helped them improve their spelling. Their reflections also indicated which activities they liked the most and which they liked the least and listed the issues with which they still needed help.

\section{Data analysis}

Within a qualitative approach, data generated in the form of words provides extensive descriptive detail, allowing for a thematic analysis and the presentation of themes that relate to the data generated. The goal of thematic analysis is to identify themes and to use these to answer the research question and it is, thus, more than a summary of the data (Maguire \& Delahunt, 2017). The data was organised to understand learners' attitudes towards spelling, and their thoughts and feelings throughout the beach spelling activity.

Following Maguire and Delahunt (2017) we first became familiar with the data through thorough reading of the fieldnotes, the observations, and the reflections. Thereafter, we identified recurring topics or words and we arranged the themes. The learners' responses that fit those themes were analysed and written up accordingly.

\section{Discussion of findings}

The analysis of the data revealed the following themes: learners' attitudes towards spelling; learners' sense of community and positive interactions; learner responsibility; and visual spelling.

\section{Learners' attitudes towards spelling}

While baseline data indicated that learners experienced difficulties with spelling in English, their attitudes towards spelling varied. Our fieldnotes revealed that when we were contemplating the possibility of the use of the beach spelling activity, Cindy immediately indicated that she would not participate because she was "scared." Her facial expression reinforced her words, and she demonstrated an overwhelming sense of fear of, and concern for, the activity as she explained that she did not want to engage in the spelling competition. This was confirmed by her comment in the reflection activity that she had been "afraid" at the thought of spelling in a competitive setting. It was clear that Cindy lacked confidence in spelling, especially in a competitive space. While she was convinced by her peers to attend, 
her reaction reinforced the importance of eliminating an environment conducive to anxiety to lower the affective filter, in line with Krashen's Affective Filter hypothesis as suggested by Abukhattala (2013), by using diverse teaching methods, instead of just pen and paper activities, to motivate learners (Du 2009).

Fieldnotes about the discussion of the beach spelling activity showed that, apart from Cindy, the other learners present at the ELC that day were extremely excited to hear about going to the beach to practise their spelling. One learner indicated that she "could not wait for Saturday" which suggested that getting out of the classroom might have been the start to changing her attitude towards spelling. Of course, just the thought of going to the beach might have been enough to generate excitement. Nevertheless, these reactions contrasted with fourteen of twenty learners having indicated that they were often bored or sleepy in their classrooms.

During the beach spelling activity, observing verbal and facial expressions proved important to understanding learners' attitudes to spelling. Cindy, who had indicated a fear of spelling, spelled very well during the beach activity, having prepared well in advance. Observations indicated that she had a smile on her face throughout the activity; this had rarely been seen in the classroom. She threw her hands in the air, shouting, "Yes!" after spelling a word correctly, thus indicating that her attitude towards the spelling task had become more positive. Ultimately, Cindy participated in the final spelling competition at school at the end of the cycle and obtained second place. It is possible that had Cindy's peers not encouraged her to attend and had she not understood her agency in preparing for the activity, she might have continued believing that she was afraid of spelling. It is also important to recognise this evidence of how Krashen's Affective Filter hypothesis works to lower learners' anxieties in using a lively, welcoming environment which, in being positive and motivating (Du, 2009), boosted learners' confidence in second language learning. Thus, going outside of classroom walls and taking part in a fun activity increased Cindy's confidence and positively affected her attitude towards spelling since she was visibly happy in the beach setting. In fact, the activity improved her competence in spelling overall, so much so that she became able to spell words she could not spell in the classroom. While Cindy might have finally succeeded with time and without interventions, her attitude to spelling and the environment in which it occurred, played a role in her success. It also confirms the idea of optimum learning occurring during playful activities, as put forward by Zosh et al. (2017).

While the beach activity resulted in a winner, the result was just one aspect of what emerged. The winner, Lolo, was elated, as could be seen in her facial expressions and words. She also noted in her reflection that she "loves" the club and "going to the beach with her friends", which, she said, she "had never done before." She noted that the activity allowed her "to improve in English." On winning, she danced with a big smile on her face and the other learners clapped their hands to congratulate her. The fieldnotes indicated that "although there was only one winner, all learners were happy with their overall performance" because their spelling had improved from the last time they engaged with this activity in the classroom, and the way they felt towards spelling had changed. 
The transformation in attitudes towards spelling in the classroom versus on the beach was evident in all learners who participated in the beach spelling track. In addition to the responses of Cindy and Lolo discussed above, Macy said, "The spelling and vocabulary cycle has helped me a lot judging by the way I used to spell and how I spell now." Nqo explained, "It improved my spelling and how to read words." Thus, we could see that lowering the affective filter through a relaxed and fun activity allowed for more input (Abukhattala, 2013) which was in this case, correct spelling. The beach activity observations and fieldnotes reflected happy learners who enjoyed a fun-filled morning at the beach and who engaged in activities that helped them to practise and improve their spelling, thus conquering their fear of it and transforming their attitudes towards it.

However, this does not mean that learners did not experience disappointment. Observations and fieldnotes reflect that Minnie, Nqo, and Jabu had sad faces and that they frowned and used gestures of frustration when they or others got spellings incorrect. This finding echoes the argument by Zosh et al. (2017) who noted that a joyful activity is not necessarily detached from negative emotions and annoyance may help learning, as was evidenced in the ELC when learners spelled a word incorrectly and could not move on to the next word. The true learning occurred when they figured out the correct spelling after the first failed attempt, albeit with the help of others, and were then happy with the outcome.

\section{Learners' sense of community and positive interactions}

Despite the activity being competition-based with a prize for the winner, learners were whispering clues and even answers, when necessary, to the learner whose turn it was to spell. The activity was fun and held at a beach and both factors seemed to shape how learners engaged with the activity which they might not have done in a classroom. However, their responses led to a positive attitude, and they ultimately improved their spelling scores in subsequent spelling activities. The positive interactions and perceptions were associated with learners' satisfaction and success (Garibay, 2015), in line with the principles of critical pedagogy that encourage support and learning from each other (Aliakbari \& Faraji, 2011). Linked to this, the Affective Filter hypothesis addresses the need to encourage social activities for the purpose of boosting learners' confidence and lowering anxiety (Du, 2009).

Observations and fieldnotes also recorded that learner support was important in making the learners feel comfortable and relieved of the stress of spelling, as was evidenced in gestures of thanks, and smiles on faces. In addition, they learned from listening to and observing other learners. Further, being actively engaged in the activity was beneficial since learners often learn well when they are actively involved in solving problems rather than merely being instructed by the teacher (Zosh et al., 2017).

Moreover, learners' written reflections revealed that the outdoor activity improved attitudes towards spelling while they spent an enjoyable time with friends. Lee wrote that she enjoyed "laughing and having fun with others" and Nqo wrote that she "[loved] it so much ... because everyone was happy" and that she learned "how to spell more words." The responses reflect how learners had linked a happy experience to improving a cognitive skill. They also 
understood how groupwork and social activities boost learning confidence and lower anxiety in line with Du (2009) who argued that making use of the Affective Filter hypothesis boosts learning confidence and lowers anxiety.

\section{Learner responsibility}

Through observation, it was discovered that a learner, Minnie, seemed to have been having a challenging time with the spelling task since she remained behind and was not happy about it. Fieldnotes from a previous activity indicated that Minnie had not completed the flashcard activity which was meant to assist learners in learning some of the words that were tested. Nonetheless, while her presence at the beach activity was positive, it was also evident that learners need to take responsibility for their learning for transformation to be successful. Minnie was able to learn this, albeit in hindsight.

The importance of learner responsibility in this study was also emphasised in Sammy's written reflection. She indicated that she "really enjoyed the day [they] went to the beach" but indicated that she was "disappointed" about not winning the spellathon at the end of the cycle, despite the beach activity helping her improve her spelling. She noted, however, that she realised that she "did not put much effort in." The reflection after the cycle allowed the learners to reflect on, and become aware of, their roles in learning. Sammy's reflection showed that she was moving towards critical consciousness since she was able to identify what went wrong and acknowledge the significance of her role in her learning.

\section{Visual spelling}

The observation and fieldnotes revealed that three learners, Lee, Cindy, and Lolo, were more comfortable spelling the words by either writing on the sand or writing in the air with their fingers, indicating the need to envisage the word to check their spelling before spelling it out verbally. Fieldnotes revealed that this learning strategy was not adopted by learners in the formal English classroom or at the ELC at school. It is possible that the formal setting of the school meant that learners responded in ways that are deemed suitable for the formal classroom. It is also possible that since learners more often write out spellings rather than speak them, writing in the sand or in the air was part of a process that was more familiar.

\section{Conclusion}

Many obstacles, such as the curriculum, overcrowded learning contexts, lack of resources, and language barriers may challenge the learning of English for second language learners. However, creating opportunities for interaction, encouraging participation, using innovative teaching methods, enabling learners to make decisions, considering learners' differences, and fostering friendliness may address these, and other, challenges (Fraser \& Treagust, cited in Barr, 2016). A sense of collegial friendship also proves useful in developing language learning and this can manifest using groupwork which improves learners' achievements and develops positive attitudes towards learning as Goss et al. (2017) have argued. In the spelling 
activity of the ELC that we have discussed in this paper, such principles served as guidelines on how to proceed.

While competitions may be frowned upon in some educational circles, in this instance, the young teenagers embraced the challenge of the friendly, supportive, fun-filled competition, and ultimately, changed their attitudes towards spelling since it encouraged them to participate and concentrate on the activity to increase their chances of winning the prize. We argue, therefore, for relaxed, positive environments using innovative interventions to complement or even replace conventional classroom activities and assessment so that optimum learning may thrive.

The beach activity revealed that learners were enthusiastic about spelling when their interests and preferences were considered. Furthermore, the relaxed, fun activity allowed learners to participate freely and removed the fears that that they shared about spelling, decreased their anxiety, and increased their motivation and self-confidence. However, what is imperative to note is that the beach needs to be recognised for what it symbolises-a relaxed, happy space with minimal rules. Such a space or atmosphere may be recreated anywhere, even in a conventional classroom, if necessary. A positive environment should provide the necessary care and support for learners, be inspirational, and encourage learners to be responsible for their learning.

\section{References}

Abukhattala, I. (2013). Krashen's five proposals on language learning: Are they valid in Libyan EFL classes? English Language Teaching, 6(1), 128-131.

Acquah, B. Y. S., \& Partey, P. A. (2014). The influence of co-curricular activities on students' performance in economics. International Journal of Educational Management, 6(6):147-160.

Al-Bereiki, S. A., \& Al-Mekhlafi, A. M. (2016). Spelling errors of Omani EFL students: Causes and remedies. Journal of Applied Linguistics and Language Research, 3(7), $20-46$.

Alexander, N., Bloch, C., Jogee, N., Guzula, X., \& Mahobe, N. (2011). Creating literate school communities: Vulindlela reading clubs. http://www.praesa.org.za/wpcontent/uploads/2016/09/Creating_Literate_School_Com munities_Vulindlela_Re-1.pdf.

Aliakbari, M., \& Faraji, E. (2011). Basic principles of critical pedagogy. https://www.researchgate.net/publication/266224451_Basic_Principles_of_Critical_P edagogy 
Aliyu, M. M., \& Danladi, G. A. (2018). Attitudes of Hausa ESL secondary school students towards spelling and writing in English. International Journal of Language Teaching and Education, 2(3), 184-194.

Al-Sobhi, B., Rashid, S. M., \& Abdulla, A. N. (2018). Arab ESL school students' attitudes towards English spelling and writing. Sage Open, 8 (1),1-11.

Barr, J. J. (2016). Developing a positive classroom environment. https://www.ideaedu.org/Portals/0/Uploads/Documents/IDEA\%20Papers/IDEA\%20P apers/PaperIDEA_61.pdf

Batker, C., Osucha, E., \& Rohrbach, A. (2017). Introduction: Critical pedagogies for a changing world. American Literature, 89(2), 213-223. https://doi.org/10.1215/00029831-3861481।

Camangian, P. R. (2015). Teach like lives depend on it: Agitate, arouse, and inspire. Urban Education, 50(4), 424-453. https://doi.org/0.1177/0042085913514591

Chamorro, M. E. G., \& Paz, L. H. B. (2017). Improving language learning strategies and performance of pre-service language teachers through a CALLA-TBLT model. PROFILE, 19(2), 101-120.

Cohen, L., Manion, L., \& Morrison, K. (2011). Research methods in education (7th ed.). Routledge.

Dewi, R. S., Kultsum, U., \& Armadi, A. (2017). Using communicative games in improving students' speaking skills. English Language Teaching, 10(1), 63-71. https://doi.org/ 10.5539/elt.v10n1p63

Du, X. (2009). The affective filter in second language teaching. Asian Social Science, 5(8), $162-165$.

Fleisch, B., Pather, K., \& Motilal, G. (2017). The patterns and prevalence of monosyllabic three-letter-word spelling errors made by South African English first additional language learners. South African Journal of Childhood Education, 7(1), 1-10.

Freire, P. (1970). Pedagogy of the oppressed. Herder \& Herder.

Garibay, J. C. (2015). Creating a positive classroom climate for diversity. https://equity.ucla.edu/wpcontent/uploads/2016/06/CreatingaPositiveClassroomClimateWeb-2.pdf

Goss, P., Sonnemann, J., \& Griffiths, K. (2017). Engaging students: Creating classrooms that improve learning. Grattan Institute. 
Graven, M. (2011). Creating new mathematical stories: Exploring opportunities within Maths clubs. In H. Venkat \& A. A. Essien (Eds.), Proceedings of 17th National Congress of the Association for Mathematical Education of South Africa (pp. 161-170). AMESA

Halabsaz, F., \& Hedayati, F. (2016). The role of critical language pedagogy in education. International Journal of Modern Language Teaching and Learning, 1(4), 137-144.

Harney, B. (2014). Critical theory. https://www.researchgate.net/publication/261697559_Critical_Theory

Hashemi, A., \& Ghalkhani, O. (2016). The impact of different teaching strategies on teaching spelling to kindergarten children. Journal of Language Teaching and Research, 7(4), 730-737.

Howie, S. J., Combrinck, C., Roux, K., Tshele, M., Mokoena, G. M., \& McLeod Palane, N. (2017). PIRLS Literacy 2016 Progress in International Reading Literacy Study 2016: South African Children's Literacy Achievement. Centre for Evaluation and Assessment.

Kakule, H. (2016). Practical applicability of Krashen's theory on English teaching and learning with reference to English teaching in Goma schools. Annales de l'UNIGOM, 6(2), 329-338.

Krashen, S. (1982). Principle and practice in second language acquisition. Pergamon Press.

Madonsela, S. (2015). Language anxiety caused by the single mode of instruction in multilingual classrooms: The case of African language learners. Africa Education Review, 12(3), 447-459. https://doi.org/10.1080/18146627.2015.1110910

Maguire, M., \& Delahunt, B. (2017). Doing a thematic analysis: A practical, step-by-step guide for learning and teaching scholars. AISHE-J: The All Ireland Journal of Teaching and Learning in Higher Education, 9(3), 3351-3364.

Mazdaee, M., \& Maftoon, P. (2012). Implementing the principles of critical pedagogy in an EFL writing class. Modern Journal of Language Teaching Methods, 2(4), 26-50.

Nath, P. R., Mohamad, M., \& Yamat, H. (2017). The effects of movies on the affective filter and English acquisition of low-achieving English learners. Creative Education, 8(8), 1357-1378. https://doi.org/10.4236/ce.2017.88096

Newbury, D. (2001). Diaries and field-notes in the research process. Research Issues in Art, Design and Media, (1), 1-17. www.wordsinspace.net/course_material/mrm/mrmreadings/riadmIssue1.pdf

Norton, B., \& Toohey, K. (2005). Critical pedagogies and language learning. Cambridge University Press. 
Pereira, A. H., Ismail, K., \& Othman, Z. (2013). A model for the Malaysian English language club activities. Procedia-Social and Behavioral Sciences, 48-56.

Pretorius, E. J., \& Spaull, N. (2016). Exploring relationships between oral reading fluency and reading comprehension amongst English second language readers in South Africa. Reading and Writing, 29(7), 1449-1471. https://doi.org/10.1007/s11145-016-9645-9

Pretorius, E. J., \& Stoffelsma, L. (2017). How is their word knowledge growing? Exploring Grade 3 vocabulary in South African township schools. South African Journal of Childhood Education, 7(1), 1-13.

Schaefer, M., \& Kotzé, J. (2019). Early reading skills related to Grade 1 English second language literacy in rural South African schools. South African Journal of Childhood Education, 9(1), 1-13.

Sibanda, J., \& Baxen, J. (2018). Third-Grade English second language teachers' vocabulary development practices. South African Journal of Childhood Education, 8(1), 1-9.

Zosh, J. N., Hopkins, E. J., Jensen, H., Liu, C., Neale, D., Hirsh-Pasek, K., \& Whitebread, D. (2017). Learning through play: A review of the evidence. LEGO Foundation. 